\title{
Supramolecular threading of peptide hydrogel fibrils
}

Article

Accepted Version

Hauptstein, N., De Leon-Rodriguez, L. M., Mitra, A. K., Hemar, Y., Kavianinia, I., Li, N., Castelletto, V., Hamley, I. W. and Brimble, M. A. (2018) Supramolecular threading of peptide hydrogel fibrils. ACS Biomaterials Science \& Engineering, 4 (8). pp. 2733-2738. ISSN 2373-9878 doi:

https://doi.org/10.1021/acsbiomaterials.8b00283 Available at https://centaur.reading.ac.uk/78115/

It is advisable to refer to the publisher's version if you intend to cite from the work. See Guidance on citing.

To link to this article DOI: http://dx.doi.org/10.1021/acsbiomaterials.8b00283 Publisher: American Chemical Society

All outputs in CentAUR are protected by Intellectual Property Rights law, including copyright law. Copyright and IPR is retained by the creators or other copyright holders. Terms and conditions for use of this material are defined in the End User Agreement.

\section{www.reading.ac.uk/centaur}

\section{CentAUR}


Central Archive at the University of Reading

Reading's research outputs online 


\title{
Supramolecular Threading of Peptide Hydrogel Fibrils
}

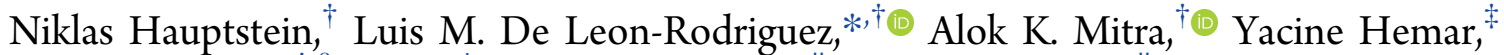 \\ Iman Kavianinia, ${ }^{\dagger, \S} \mathrm{Na} \mathrm{Li}{ }^{\perp}$ Valeria Castelletto, ${ }^{\circledR \odot}$ Ian W. Hamley, ${ }^{\| \odot}$ and Margaret A. Brimble ${ }^{* \dagger,+, \S_{\odot}}$ \\ ${ }^{\dagger}$ School of Biological Sciences and ${ }^{\S}$ Maurice Wilkins Centre for Molecular Biodiscovery, The University of Auckland, 3A Symonds \\ Street, Auckland 1010, New Zealand \\ ${ }^{\ddagger}$ School of Chemical Sciences, The University of Auckland, 23 Symonds Street, Auckland 1010, New Zealand \\ ${ }^{\perp}$ National Centre for Protein Science Shanghai, Chinese Academy of Sciences, Shanghai 201204, China \\ "School of Chemistry, Food Science and Pharmacy, University of Reading, Whiteknights, Reading RG6 6AF, United Kingdom
}

\section{Supporting Information}

\begin{abstract}
There is an increasing demand for biocompatible materials in biomedical applications. Herein, we report a modified $\alpha$-helical decapeptide segment from the cardiac troponin $\mathrm{C}$, which self-assembles into fibers with a secondary $\beta$-sheet structure. These fibers cross-link via a novel supramolecular threading mechanism which results in an atypical stiff hydrogel $\left(G^{\prime} \approx 13 \mathrm{kPa}\right)$. In this work, we provide a first insight into the understanding of such remarkable cross-

linking mechanism, which will aid in the development of new biomaterials with unique properties.
\end{abstract} (1)

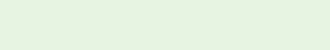

KEYWORDS: hydrogels, supramolecular, threading, biomaterials, fibrils, self-assembly

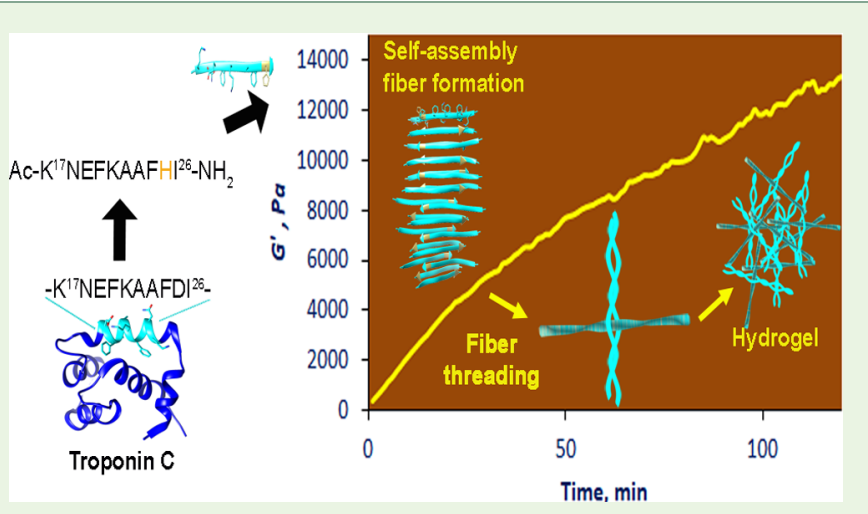

Time, $\min$
$\mathrm{P}$ eptide-based hydrogels are a type of biomaterial that have attracted considerable interest because they provide the opportunity to introduce a large variety of functionality within a biocompatible framework. Hydrogel formation originates from the hierarchical self-assembly of peptides, driven by intraand intermolecular noncovalent interactions. The self-assembly motif consists of fibrils/fibers, usually with a $\beta$-sheet secondary structure, entangled in a three-dimensional macroscopic network that traps water molecules. ${ }^{1}$ Fibril entanglement has an important effect in the mechanical properties of a hydrogel (i.e., highly entangled peptides fibrils lead to stiffer gels). ${ }^{2}$ In practice, the amino acid sequences of most peptide forming hydrogels are either artificially designed or naturally derived. Naturally derived peptides are preferred from a biocompatibility perspective; however, when pursuing a particular application, a modification of the native peptide sequence may be required.

We recently synthesized a 23-residue peptide (1) (Figure 1) that self-assembled into fibers with a $\beta$-sheet secondary structure and formed hydrogels at acidic $\mathrm{pH}$. Interestingly, 1 is derived from an $\alpha$-helical sequence of the human cardiac protein troponin C. ${ }^{3}$ Furthermore, the amino acid sequence of 1 comprises regions containing alternating hydrophobic and hydrophilic amino acids similar to those in designed $\beta$-sheet peptide hydrogels. ${ }^{1}$ However, in $\mathbf{1}$ there are also residues that break the aforementioned residue alternations further highlighting their importance for understanding the mechanism of hydrogel formation in 1 . Toward this end, we set out to determine if there is a shorter segment within $\mathbf{1}$ that drives hydrogel formation and if this can be achieved at physiological $\mathrm{pH}$, an important characteristic when pursuing biological applications. We focused our attention on the decapeptide $\mathrm{K}^{17}$ NEFKAAFDI ${ }^{26}$ (2) (Figure 1), as this contains alternating hydrophobic/hydrophilic residues (except for $\mathrm{Ala}^{23}$ ); it has an even number of acidic ( Glu ${ }^{19}$ and $\mathrm{Asp}^{25}$ ) and basic (Lys ${ }^{17,21}$ ) amino acids, which might lead to formation of hydrogels at neutral $\mathrm{pH}$ (calculated $\mathrm{pI}=4.14$ and 6.56 for 1 and 2, respectively) $)^{4}$ and it contains two phenylalanine residues which are known to favor assembly through $\pi-\pi$ interactions. ${ }^{5}$

Peptide 2 was successfully synthesized (Figure S1) via automated Fmoc solid phase peptide synthesis protocols. Peptide 2 formed weak hydrogels at concentrations $\geq 5$ wt $\%$ in a $\mathrm{pH}$ range between 3.8 and 4.8 , that is similar to the $\mathrm{pH}$ range in which formation of gels of $\mathbf{1}$ was observed. However, one would have expected 2 to form hydrogels near to neutral $\mathrm{pH}$, as noted above. Therefore, peptides $\mathbf{2 a}$ and $\mathbf{2 b}$ (Figure 1 and Figures S2 and S3) were prepared to gain further insight on the effect of the terminal charged groups on hydrogel formation. Peptide 2a contains a C-amidated terminal residue and peptide 2b comprises $\mathrm{N}$-acylated and $\mathrm{C}$-amidated termini residues.

Received: March 7, 2018

Accepted: June 19, 2018

Published: June 19, 2018 


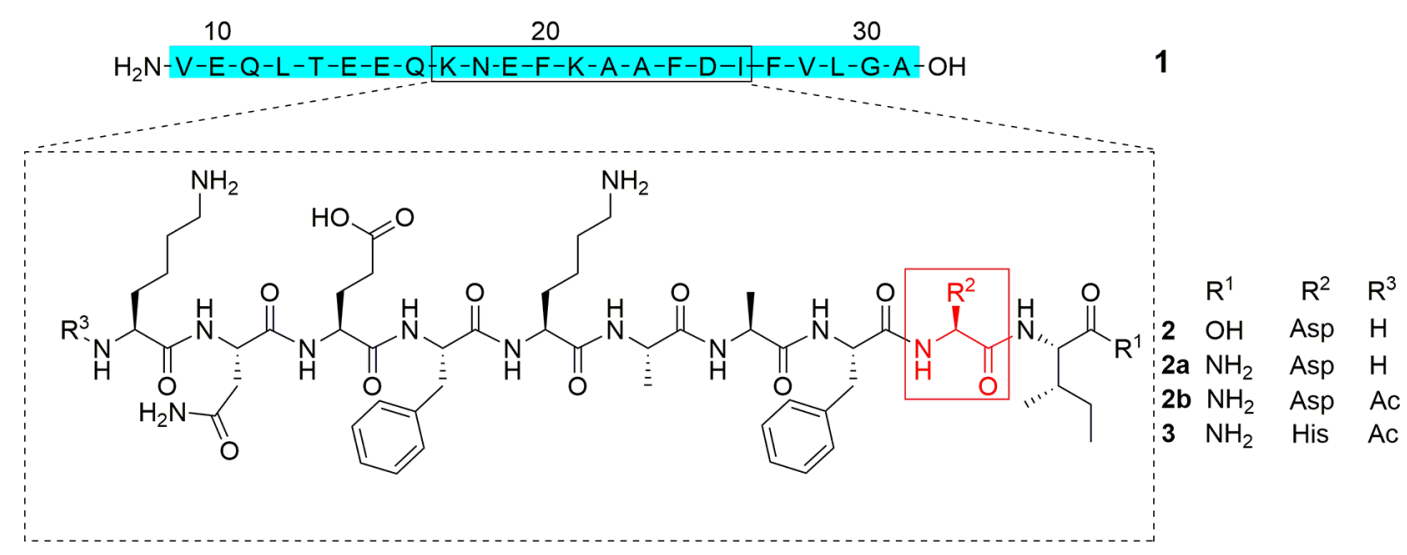

Figure 1. Peptide sequences discussed in this work.

Both peptides (2a, 2b) formed hydrogels at concentrations $\geq 2.5$ wt $\%$ in a $\mathrm{pH}$ range between 3.8 and 5.5, thus showing that the terminal charged groups have little effect on hydrogelation. This result suggests that the acidic side chains of 2 prevent peptide assembly when deprotonated at neutral $\mathrm{pH}$ possibly due to unfavorable electrostatic interactions. This problem was specifically attributed to $\mathrm{Asp}^{25}$, given its isolation from the rest of the ionic amino acids in the peptide chain $\left(\mathrm{Glu}^{19}\right.$, Lys $^{17,21}$ ) (Figure 1). To address this issue, we set to replace $\mathrm{Asp}^{25}$ in $\mathbf{2 b}$. Substitution of $\mathrm{Asp}^{25}$ with hydrophobic amino acids, such as Ala, Leu, etc., was not considered as these will alter the alternating hydrophobic and hydrophilic amino acids requirement for hydrogel formation. Thus, considering that one of our goals is to form hydrogels at physiological $\mathrm{pH}$ we prepared peptide 3 (Figure 1 and Figure S4) where $\mathrm{Asp}^{25}$ was substituted with $\mathrm{His,}$ a residue with an imidazole side chain with a close to neutral $\mathrm{p} K_{\mathrm{a}}(\sim 6)$. Furthermore, His attracted our attention given that it is an amino acid that has been poorly studied in the field of peptide hydrogels.

Peptide 3 formed clear hydrogels within 5-15 min of sample preparation at a $1 \mathrm{wt} \%$ concentration in $50 \mathrm{mM}$ buffer in the $\mathrm{pH}$-range $5.8-8.0$ (calculated peptide $\mathrm{pI}=8.77$ ) but failed to form gels at concentrations lower than 0.5 wt \%. Furthermore, hydrogel formation was not affected by the presence of physiologically relevant inorganic salts, such as $\mathrm{NaCl}(75 \mathrm{mM}), \mathrm{MgCl}_{2}(25 \mathrm{mM})$, and $\mathrm{CaCl}_{2}$ (25 mM), but gelation slowed down (gels form after $48 \mathrm{~h}$ of sample preparation at $\mathrm{RT}$ ) in the presence of divalent transition metals (e.g., $\mathrm{ZnCl}_{2} 25 \mathrm{mM}$ ) (Figure S5A). The latter result was attributed to metal coordination by the His residues, which in turn might force the peptide into a conformation that alters the assembly process. ${ }^{6}$ Interestingly, in another experiment, we observed that a gel preformed in the absence of salts remained intact after being in contact with a solution of $\mathrm{CuSO}_{4} 250 \mathrm{mM}$ for $24 \mathrm{~h}$. The divalent copper ion forms strong coordination complexes with His residues, hence the fact that hydrogel 3 remains intact in the presence of $\mathrm{Cu}^{2+}$ highlights the important role of His in peptide assembly (Figure S5B). ${ }^{7}$

Rheology was used to study the viscoelastic properties of the hydrogels described herein. A series of time sweep experiments at constant shear strain $(\gamma=0.2 \%)$ and angular frequency $(\omega=$ $\left.6 \mathrm{rad} \mathrm{s}^{-1}\right)$ were carried out first at $37^{\circ} \mathrm{C}$. A large strain step $(\gamma$ $=1000 \%$ ) followed after each experiment in order to determine the recoverability of the system. The time sweep experiments showed the formation of gels, which are characterized by an elastic module $\left(G^{\prime}\right)$ significantly larger than the viscous module $\left(G^{\prime \prime}\right)$, for 2 (5 wt \%), 2a (2.5 wt \%), $2 \mathbf{b}(2.5 \mathrm{wt} \%)$, and 3 (1 wt \%) with a $G^{\prime}$ of $15,300,1000$, and $\sim 13000 \mathrm{~Pa}$, respectively (Figure 2 and Figures S6-S9). It is

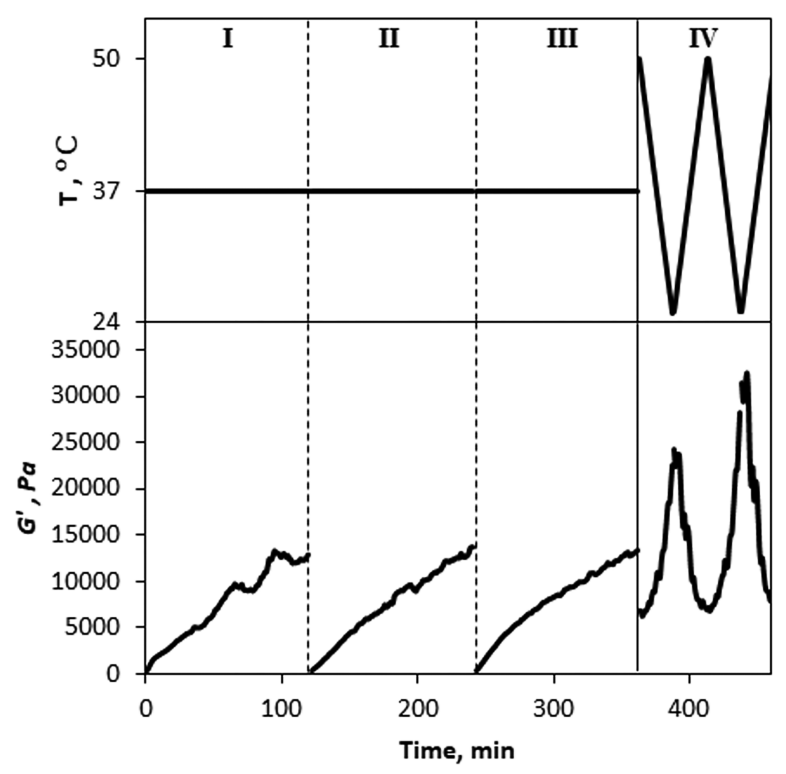

Figure 2. Storage modulus $\left(G^{\prime}\right)$ of 1 wt \% peptide 3 hydrogel in 50 $\mathrm{mM}$ Tris buffer $\mathrm{pH} 7.4$ as a function of time $\left(6 \mathrm{rad} . \mathrm{s}^{-1}, 0.2 \%\right.$ strain). Region I, II, and III correspond to time sweep at constant temperature experiments and region IV corresponds to a temperature ramp experiment. Vertical dashed lines indicate the time point when a large strain step $(\gamma=1000 \%)$ was applied.

important to note that the $G^{\prime}$ of hydrogel 3 is $\sim 3$-fold larger than that of $1\left(G^{\prime} \approx 3.9 \mathrm{kPa}\right)^{3}$ and it is larger than that of many other analogue systems reported in the literature. ${ }^{1}$ Furthermore, only hydrogels $\mathbf{2} \mathbf{b}$ and $\mathbf{3}$ presented shear-thinning properties, suggesting that $\mathrm{N}$ and C-terminal capping is necessary to warrant the regeneration of the supramolecular structure.

Next, a series of temperature sweep ramp $\left(25-50{ }^{\circ} \mathrm{C}\right)$ experiments were performed in order to determine the thermal stability of the hydrogels. Peptide hydrogels $\mathbf{2 a}, \mathbf{2} \mathbf{b}$, and $\mathbf{3}$ presented a thermoreversible behavior characterized by an increase in $G^{\prime}$ when decreasing temperature, while an opposite trend was recorded with an increase in temperature (Figure 2 and Figures S6-S9). A similar behavior has been reported for other peptide hydrogels, where increases in $G^{\prime}$ appear to be 
driven by an increase in conventional interfibrillar cross-links. ${ }^{8}$ The change in $G^{\prime}$ with temperature was larger for peptide 3 (up to 4-fold) than for $\mathbf{2 a}$ and $\mathbf{2 b}$ (up to 2.5-fold), and this could be attributed to immobilization of a larger number of fibers per cross-link for the threaded fibers relative to the single fibril/fiber nanostructure. An angular frequency sweep experiment at constant shear strain $(\gamma=0.2 \%)$ showed that both $G^{\prime}$ and $G^{\prime \prime}$ are independent of the frequency, up to $10 \mathrm{rad} \mathrm{s}^{-1}$ for $\mathbf{2}$ (Figure S10) and up to $100 \mathrm{rad} \mathrm{s}^{-1}$ for $\mathbf{2 a}, \mathbf{2} \mathbf{b}$ and $\mathbf{3}$ (Figures S11-S13). The linear viscoelastic regime of the system was stablished from shear strain amplitude sweep experiments $(\omega=$ $6 \mathrm{rad} \mathrm{s}^{-1}$ ), which showed a constant $G^{\prime}$ and $G^{\prime \prime}$ up to $\gamma=1 \%$ for all the peptide hydrogels (Figures S14-S17).

Finally, we demonstrated that exposure of hydrogel 3 to a $\mathrm{CuSO}_{4}$ solution as described before, did not have a negative effect on the stiffness of the gel, but rather increased it. (Figure S18).

The secondary structure of hydrogel 3 was assessed by FTIR. The IR spectrum of a 1 wt \% gel of 3 in $\mathrm{H}_{2} \mathrm{O}$ showed a peak at $1614 \mathrm{~cm}^{-1}$ (Figure 3) and a shoulder at $1622 \mathrm{~cm}^{-1}$

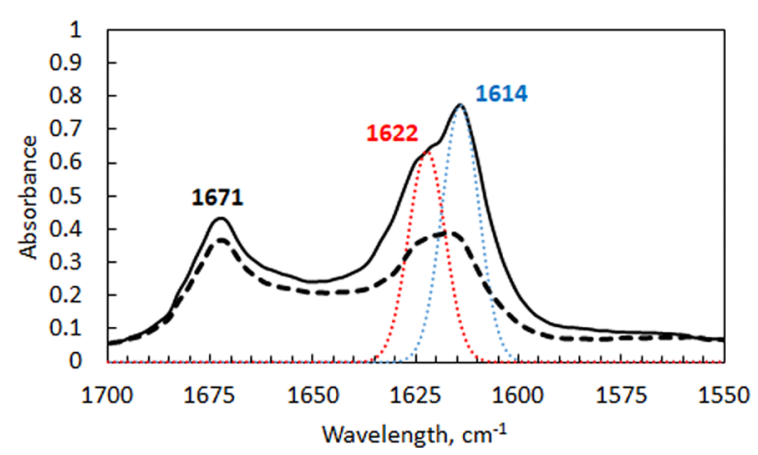

Figure 3. Transmission FTIR spectrum of a hydrogel of 3 at 1.0 (solid black line) and at 0.5 (dashed black line) wt \% in $\mathrm{H}_{2} \mathrm{O}$. The cyan and red dotted traces correspond to Gaussian plots fitted to the IR peak of 3 at 1 wt \%.

(determined after fitting the IR signal to two Gaussian curves, Table S1), which agrees with a $\beta$-sheet structure. ${ }^{9}$ Importantly, the IR spectrum of 3 in $\mathrm{D}_{2} \mathrm{O}$ did not show a significant shift ( 1624 and $1616 \mathrm{~cm}^{-1}$ ) relative to the peaks observed in $\mathrm{H}_{2} \mathrm{O}$ (Figure S19), which suggests that these absorption bands correspond to vibrations of the amide groups in the peptide's backbone and not to the amide of $\mathrm{Asn}^{18}$ or of the $\mathrm{C}=\mathrm{C}$ in the imidazole ring of $\mathrm{His}^{25} .{ }^{10}$ Hence, the two signals observed in the FTIR were assigned to $\beta$-sheet assemblies with different twist angles. ${ }^{11}$ The additional signal observed at $\sim 1671 \mathrm{~cm}^{-1}$ arises from a strong contribution from trifluoroacetate counterions. ${ }^{12}$ The IR spectra of $\mathbf{2}, \mathbf{2} \mathbf{a}$, and $\mathbf{2 b}$ in $\mathrm{D}_{2} \mathrm{O}$ showed a signal at $1615 \mathrm{~cm}^{-1}$ and a shoulder at $1630 \mathrm{~cm}^{-1}$ but of lesser intensity than those of 3 (Figure S20), thus confirming a $\beta$ sheet structure.

As mentioned before, peptide 3 did not form gels at concentrations lower than $0.5 \mathrm{wt} \%$, this was evidenced by a decrease of $\beta$-sheet structural contribution in the FTIR spectrum (Figure 3). Furthermore, the circular dichroism spectrum of a hydrogel of 3 exhibited positive signals at 205 and $240 \mathrm{~nm}$ and a negative signal at $\sim 220 \mathrm{~nm}$ (Figure S21), which were attributed to $\mathrm{n} \rightarrow \pi \tau o \pi \rightarrow \pi^{*}$ aromatic transitions and a $\beta$-sheet structure, respectively. However, the peak at $\sim 220 \mathrm{~nm}$ was not observed for 0.1 and $0.5 \mathrm{wt} \%$ solutions of 3, which suggests a predominant random structure. ${ }^{13}$

Transmission electron microscopy (TEM) images of 3 showed a fibrillar structure typical of peptide hydrogels (Figure 4 and Figure S22). Remarkably, the TEM images exhibited what appears to be a fiber threaded into another fiber, a feature that has not been reported to date to the best of our knowledge in the peptide hydrogel field. In TEM images of samples prepared from a diluted solution of 3 (100-fold dilution from a 0.75 wt \% solution) (Figure 4) the threaded fiber appeared twisted with a maximum diameter of $12.0 \pm 0.8 \mathrm{~nm}$ and a pitch of $149.0 \pm 1.1 \mathrm{~nm}$. The TEM image showed that the threading fiber was composed of two intertwined protofibrils with a $5.4 \pm$ $0.2 \mathrm{~nm}$ diameter and with an average interfibril separation of $3.4 \pm 0.6 \mathrm{~nm}$. This space is wide enough to fit a fiber composed of a bilayer of assembled $\beta$-sheet strands, which have a reported width of $2.7 \mathrm{~nm} .{ }^{14}$ Additionally, the fiber diameter at the point where the fibers thread was wider (14.6 $\pm 0.3 \mathrm{~nm}$ ) than the average diameter in the remaining sections of the fiber $(12.2 \pm 1.2 \mathrm{~nm})$, which again agrees with the presence of a threaded fiber (Figure S23). Cryo-TEM images of 3 (Figure S24) showed similar features to those observed in TEM.

By way of contrast, TEM images of $\mathbf{2} \mathbf{a}$ showed individual twisted fibrils with a diameter of $3.6 \pm 0.7 \mathrm{~nm}$ (Figure S25) and $\mathbf{2 b}$ showed an untwisted laminated fiber morphology with
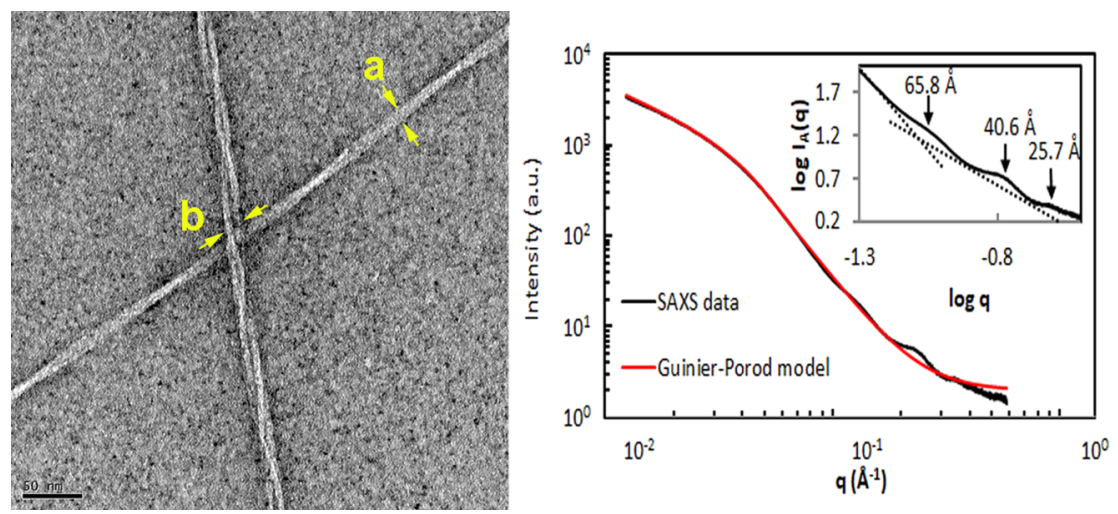

Figure 4. (Left) Transmission electron micrographs of a 100 -fold diluted sample of $0.75 \mathrm{wt} \%$ hydrogel of 3 stained with $2 \%$ uranyl acetate, $a=$ $12.0 \pm 0.8 \mathrm{~nm}$ and $b=14.6 \pm 0.3 \mathrm{~nm}$ (threading point). The black scale bar corresponds to $50 \mathrm{~nm}$. (Right) Intensity vs $q$ plot of the SAXS profile at room temperature of a hydrogel of 3 prepared at $1 \mathrm{wt} \%$ in buffer. (Plot inset) $\log I(q)$ vs $\log q$ plot of the Porod region of the SAXS profile. Dashed tangential lines have been added to highlight the presence of peaks. 


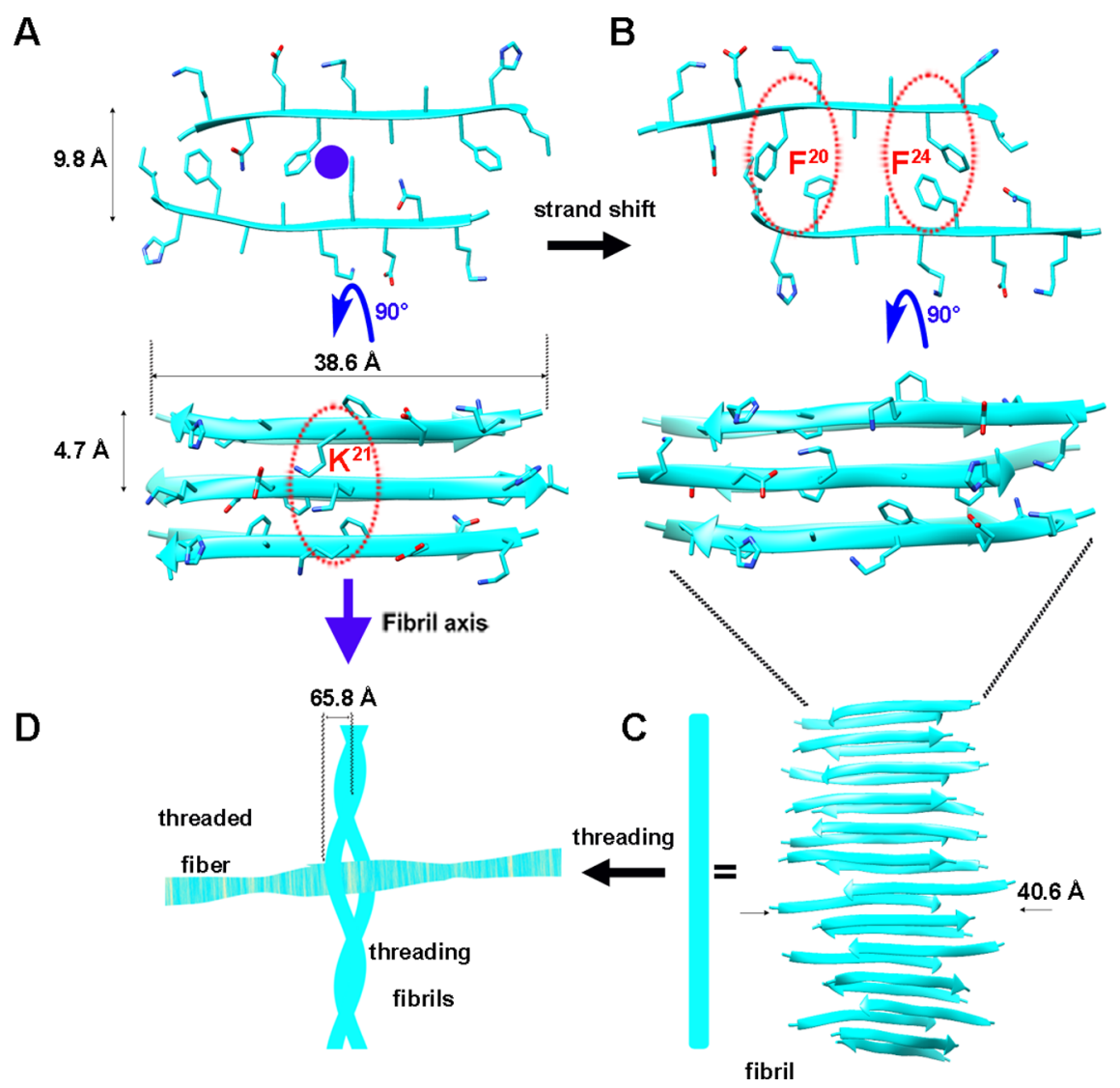

Figure 5. Model of fibril formation for peptide 3. (A) Two stacked (top) and three adjacent unshifted antiparallel $\beta$-sheets (bottom). (B) Two stacked (top) and three adjacent antiparallel shifted $\beta$-sheets (bottom). Stacked and adjacent $\beta$-strands are viewed along the fibril axes and through an axis perpendicular to the fibril axis, respectively. Relevant residues' interactions are enclosed in dotted red ovals. (C) Top view of a longer fibril. (D) Schematics of fibrils threading a fiber. Figures A-D are represented at different scales. The peptide backbones are rendered as ribbons, and atoms colored as follows: nitrogen (dark blue), oxygen (red), and carbon (light blue).

fibrils with a diameter of $3.9 \pm 0.2 \mathrm{~nm}$ (Figure S26). Individual fibers of 2 prepared from diluted samples could not be observed, which can be explained by the very high peptide concentration $(<5 \mathrm{wt} \%)$ of peptide required for gel formation, something that leads to heavily stained aggregates. Moreover, it is important to keep in mind that TEM images are 2D projection images of the sample hence a $3 \mathrm{D}$ interpretation is not straightforward, and that the sample preparation required for TEM imaging (dilution, surface deposition and drying or freezing) especially with negative staining may alter sample morphology relative to the one in the solution state. ${ }^{15}$ Hence, to validate the atypical morphologies of 3 observed in TEM we proceeded to study the structure of a hydrogel of 3 at $1 \mathrm{wt} \%$ by SAXS. A plot of the scattering intensity, $I$, as a function of the scattering vector, $q$, in logarithmic scale is shown in Figure 4. Based on the TEM images we depict fibers of $\mathbf{3}$ as thin rods. In this context the threading fibers will be rods widening in those sections where fiber threading occurs. Hence, the SAXS profile was fitted to the Guinier-Porod model which is particularly suited for the analysis of asymmetric objects (e.g., rods). ${ }^{16,17}$ A diameter of $116.2 \pm 2.0 \AA\left(R_{\mathrm{g}}=41.1 \pm 0.7\right.$ $\AA$ ) was calculated (see the Supporting Information), which is close to the average diameter of the fibers observed in TEM. Additionally, three broad peaks were detected in the Porod region of the $I / q$ plot. These peaks were more clearly observed when the SAXS data was represented in a $\log I(q)$ vs $\log q$ graph (inset plot in Figure 4). Using the position of the peaks' maximum $(q)$ and the Bragg law $(d=2 \pi / q)$ three distances corresponding to $65.8,40.6$, and $25.7 \AA$ were calculated. ${ }^{15}$

The $65.8 \AA$ distance comes close to the sum of the length of the peptide in an extended $\beta$-sheet conformation and the width of a bilayer of stacked $\beta$-sheets. Interestingly, the $65.8 \AA$ distance also comes near to half the width of the threading fiber in the threading zone $(14.6 \pm 0.3 \mathrm{~nm})$, in accord with the presence of the threading point observed in TEM (Figure 4). The second peak (40.6 A) approximates the in-plane length of the 10-amino-acid peptide in the extended $\beta$-sheet conformation (38.6 $\AA$ ) (Figure 5A, C), which is close to the diameter of the single fibrils observed in TEM. The value of $25.7 \AA$ is attributed to a strand distance repeat which is consistent with a cross- $\beta$-sheet structure. ${ }^{18}$ Interestingly, a diameter of $77.9 \pm 3.0 \AA\left(R_{\mathrm{g}}=27.6 \pm 1.0 \AA\right)$ was calculated (see the Supporting Information), when SAXS data of a hydrogel of 3 at 5 wt \% was fitted to the Guinier-Porod model described before (Figure S27). Furthermore, in this case no other signals were observed in the Porod region. The $77.9 \AA$ diameter approximates half the length of the threading fiber in the threading zone indicated above. Thus, we conclude that the supramolecular threading is the major morphology in the macro network at high peptide concentration, hence suggesting that threading is a concentration-dependent phenomenon.

X-ray diffraction of a dried hydrogel sample of 3 presented reflections at 4.7 and $9.8 \AA$ (Figure S28), which are characteristic of $\beta$-sheets and represent the interstrand spacing 
and the spacing between $\beta$-sheets stacked in a bilayer within the fibril, respectively. ${ }^{19}$ Another reflection at $3.8 \AA$ was also observed, which has been previously assigned to the $C^{\alpha}-C^{\alpha}$ spacing of twisted $\beta$-sheets.

Considering the structural information discussed herein, we propose the following molecular model of fibril formation of 3 . First, the $9.8 \AA$ reflection observed in XRD agrees with the inplane distance of a bilayer of planar $\beta$-strands (Figure 5A), stacked by intermolecular interactions of residues in the hydrophobic face of the amphiphilic peptides. Second, we propose that the peptide adopts an antiparallel $\beta$-sheet arrangement with an interstrand distance of $4.7 \AA$ (Figure $5 \mathrm{~A})$. We envision that a parallel structure will align the positively charged $\mathrm{Lys}^{17,21}$ residues of adjacent parallel strands, thus creating a strong unfavorable electrostatic repulsive interaction. Moreover, it is worth noting that an antiparallel organization will still lead to an unfavorable electrostatic interaction between the $\mathrm{Lys}^{21}$ residues of adjacent $\beta$-sheets. Thus, we suggest that such unfavorable interaction will be reduced by a registry shift between adjacent antiparallel $\beta$ sheets. This $\beta$-strand displacement not only separates the Lys ${ }^{21}$ residues but it also increases the number of possible interactions among the Phe residues present in the hydrophobic face of the peptide bilayer (Figure 5B).

A model for fiber threading is more complex to elucidate. Our suggestion is as follows. We propose that peptide 3 initially self-assembles into fibrils which hierarchically interact to form a fiber. Two scenarios could explain fiber threading: (1) two sets of intertwining fibrils cross paths and hence threading occurs (interthreading) or (2) there is a nascent fibril/fiber formation from within the spacing between two intertwining fibrils (intrathreading). The fact that threaded fibers were observed in TEM images of highly diluted samples of peptide 3 hydrogel supports the intrathreading mechanism, because the probability of two fibers crossing paths should be minimal under high dilution. However, fibers that were in the process of intertwining were also observed in TEM (Figure S22), hence the interthreading mechanism cannot be discarded.

At this point, one can conclude that fibril supramolecular threading is a contributor for the high stiffness of hydrogel 3, especially when considering the relatively low stiffness of $\mathbf{2 b}$ where fibril-threading was not detected. Unlike their polymeric counterparts, where chemical or physical cross-linking confers the elastic properties of gels, the presence of topological interactions among fibrils/fibers and or branching nodes in peptide hydrogels has been recognized as the feature that leads to gel formation. ${ }^{21,22}$ In this work, we uncovered another type of cross-linking phenomena, fiber threading, which emerges as a possible tool to enhance the mechanical properties of the typically soft peptide hydrogels. More work is underway to better understand the molecular basis that drives fibril threading. Such a knowledge could facilitate discovery of biomaterials possessing stiffness that is optimum for biological applications.

\section{ASSOCIATED CONTENT}

\section{S Supporting Information}

The Supporting Information is available free of charge on the ACS Publications website at DOI: 10.1021/acsbiomaterials. 8 b00283.
Details of the synthesis protocol, hydrogel preparation, FTIR, XRD, TEM, cryo-TEM, SAXS experimental procedures, and data fitting models (PDF)

\section{AUTHOR INFORMATION}

\section{Corresponding Authors}

*E-mail: m.brimble@auckland.ac.nz.

*E-mail: 1.deleon@auckland.ac.nz.

ORCID

Luis M. De Leon-Rodriguez: 0000-0001-6130-724X

Alok K. Mitra: 0000-0003-0891-5697

Valeria Castelletto: 0000-0002-3705-0162

Ian W. Hamley: 0000-0002-4549-0926

Margaret A. Brimble: 0000-0002-7086-4096

Notes

The authors declare no competing financial interest.

\section{ACKNOWLEDGMENTS}

We thank G.L, Y.L., and H.W, at the BL19U2 beamline (NCPSS and SSRF) for assistance during SAXS data collection. Evgeny Bogomolny and Othman Rechiche are thanked for contributing to the recording of the TEM images. IWH and VC were supported by EPSRC Platform Grant EP/ L020599/1. This work benefited from the use of the SasView application, originally developed under NSF Award DMR$0520547 .{ }^{17}$ SasView also contains code developed with funding from the EU Horizon 2020 programme under the SINE2020 project Grant 654000.

\section{REFERENCES}

(1) De Leon Rodriguez, L. M.; Hemar, Y.; Cornish, J.; Brimble, M. A. Structure-mechanical property correlations of hydrogel forming $\beta$ sheet peptides. Chem. Soc. Rev. 2016, 45 (17), 4797-4824.

(2) Jonker, A. M.; Löwik, D. W. P. M.; Van Hest, J. C. M. Peptideand protein-based hydrogels. Chem. Mater. 2012, 24 (5), 759-773.

(3) De Leon-Rodriguez, L. M.; Kamalov, M.; Hemar, Y.; Mitra, A. K.; Castelletto, V.; Hermida-Merino, D.; Hamley, I. W.; Brimble, M. A. A peptide hydrogel derived from a fragment of human cardiac troponin C. Chem. Commun. 2016, 52 (21), 4056-4059.

(4) Kozlowski, L. P. IPC - Isoelectric Point Calculator. Biol. Direct 2016, 11, 55.

(5) Gazit, E. A possible role for $\pi$-stacking in the self-assembly of amyloid fibrils. FASEB J. 2002, 16 (1), 77-83.

(6) Pan, K.; Yi, C. W.; Chen, J.; Liang, Y. Zinc significantly changes the aggregation pathway and the conformation of aggregates of human prion protein. Biochim. Biophys. Acta, Proteins Proteomics 2015, 1854 (8), 907-918.

(7) Brännström, K.; Islam, T.; Sandblad, L.; Olofsson, A. The role of histidines in amyloid $\beta$ fibril assembly. FEBS Lett. 2017, 591 (8), $1167-1175$.

(8) Pochan, D. J.; Schneider, J. P.; Kretsinger, J.; Ozbas, B.; Rajagopal, K.; Haines, L. Thermally reversible hydrogels via intramolecular folding and consequent self-assembly of a de novo designed peptide. J. Am. Chem. Soc. 2003, 125 (39), 11802-11803.

(9) Kong, J.; Yu, S. Fourier transform infrared spectroscopic analysis of protein secondary structures. Acta Biochim. Biophys. Sin. 2007, 39 (8), 549-559.

(10) Barth, A. The infrared absorption of amino acid side chains. Prog. Biophys. Mol. Biol. 2000, 74 (3-5), 141-173.

(11) Zandomeneghi, G.; Krebs, M. R. H.; McCammon, M. G.; Fändrich, M. FTIR reveals structural differences between native $\beta$ sheet proteins and amyloid fibrils. Protein Sci. 2004, 13 (12), 33143321. 
(12) Pelton, J. T.; McLean, L. R. Spectroscopic Methods for Analysis of Protein Secondary Structure. Anal. Biochem. 2000, 277 (2), 167176.

(13) Cheng, G.; Castelletto, V.; Jones, R. R.; Connon, C. J.; Hamley, I. W. Hydrogelation of self-assembling RGD-based peptides. Soft Matter 2011, 7 (4), 1326-1333.

(14) Nagy, K. J.; Giano, M. C.; Jin, A.; Pochan, D. J.; Schneider, J. P. Enhanced mechanical rigidity of hydrogels formed from enantiomeric peptide assemblies. J. Am. Chem. Soc. 2011, 133 (38), 14975-14977. (15) Guilbaud, J. B.; Saiani, A. Using small angle scattering (SAS) to structurally characterise peptide and protein self-assembled materials. Chem. Soc. Rev. 2011, 40 (3), 1200-1210.

(16) Hammouda, B. A new Guinier-Porod model. J. Appl. Crystallogr. 2010, 43 (4), 716-719.

(17) Doucet, M.; et al.. SasView Version 4.1; DOI: 10.5281/ zenodo.438138.

(18) Blake, C.; Serpell, L. Synchrotron X-ray studies suggest that the core of the transthyretin amyloid fibril is a continuous $\beta$-sheet helix. Structure 1996, 4 (8), 989-998.

(19) Squires, A. M.; Devlin, G. L.; Gras, S. L.; Tickler, A. K.; MacPhee, C. E.; Dobson, C. M. X-ray scattering study of the effect of hydration on the cross- $\beta$ structure of amyloid fibrils. J. Am. Chem. Soc. 2006, 128 (36), 11738-11739.

(20) Castelletto, V.; Hamley, I. W.; Hule, R. A.; Pochan, D. Helicalribbon formation by a $\beta$-amino acid modified amyloid $\beta$-peptide fragment. Angew. Chem., Int. Ed. 2009, 48 (13), 2317-2320.

(21) Yucel, T.; Micklitsch, C. M.; Schneider, J. P.; Pochan, D. J. Direct Observation of Early-Time Hydrogelation in $\beta$-Hairpin Peptide Self-Assembly. Macromolecules 2008, 41 (15), 5763-5772.

(22) Raghavan, S. R.; Douglas, J. F. The conundrum of gel formation by molecular nanofibers, wormlike micelles, and filamentous proteins: Gelation without cross-links? Soft Matter 2012, 8 (33), 8539-8546. 